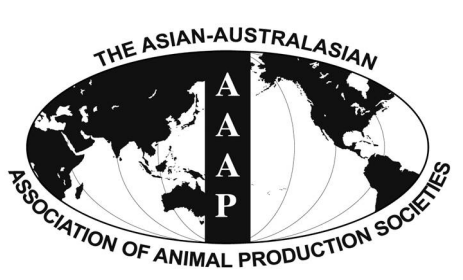

Open Access

Asian Australas. J. Anim. Sci.

Vol. 29, No. $9:$ 1287-1293 September 2016

http://dx.doi.org/10.5713/ajas.15.0653

www.ajas.info

pISSN 1011-2367 elSSN 1976-5517

\title{
The Use of Fermented Soybean Meals during Early Phase Affects Subsequent Growth and Physiological Response in Broiler Chicks
}

\author{
S. K. Kim, T. H. Kim, S. K. Lee, K. H. Chang ${ }^{1}$, S. J. Cho ${ }^{1}$, K. W. Lee, and B. K. An* \\ Department of Animal Science and Technology, Konkuk University, Seoul 143-701, Korea
}

\begin{abstract}
The objectives of this experiment was to evaluate the subsequent growth and organ weights, blood profiles and cecal microbiota of broiler chicks fed pre-starter diets containing fermented soybean meal products during early phase. A total of nine hundred 1 -d-old chicks were randomly assigned into six groups with six replicates of 25 chicks each. The chicks were fed control pre-starter diet with dehulled soybean meal (SBM) or one of five experimental diets containing fermented SBM products (Bacillus fermented SBM [BF-SBM], yeast by product and Bacillus fermented SBM [YBF-SBM]; Lactobacillus fermented SBM 1 [LF-SBM 1]; Lactobacillus fermented SBM 2 [LF-SBM 2]) or soy protein concentrate (SPC) for $7 \mathrm{~d}$ after hatching, followed by 4 wk feeding of commercial diets without fermented SBMs or SPC. The fermented SBMs and SPC were substituted at the expense of dehulled SBM at 3\% level on fresh weight basis. The body weight (BW) during the starter period was not affected by dietary treatments, but BW at $14 \mathrm{~d}$ onwards was significantly higher $(\mathrm{p}<0.05)$ in chicks that had been fed BF-SBM and YBF-SBM during the early phase compared with the control group. The feed intake during grower and finisher phases was not affected $(\mathrm{p}>0.05)$ by dietary treatments. During total rearing period, the daily weight gains in six groups were 52.0 (control), 57.7 (BF-SBM), 58.5 (YBF-SBM), 52.0 (LF-SBM 1), 56.7 (LF-SBM 2), and $53.3 \mathrm{~g} / \mathrm{d}$ (SPC), respectively. The daily weight gain in chicks fed diet containing BF-SBM, YBF-SBM, and LF-SBM 2 were significantly higher values $(\mathrm{p}<0.001)$ than that of the control group. Chicks fed BF-SBM, YBF-SBM, and LF-SBM 2 had significantly lower $(p<0.01)$ feed conversion ratio compared with the control group. There were no significant differences in the relative weight of various organs and blood profiles among groups. Cecal microbiota was altered by dietary treatments. At $35 \mathrm{~d}$, chicks fed on the pre-starter diets containing BF-SBM and YBF-SBM had significantly increased $(\mathrm{p}<0.001)$ lactic acid bacteria, but lowered Coli-form bacteria in cecal contents compared with those fed the control diet. The number of Bacillus spp. was higher $(\mathrm{p}<0.001)$ in all groups except for LF-SBM 1 compared with control diet-fed chicks. At 7 d, jejunal villi were significantly lengthened $(p<0.001)$ in chicks fed the fermented SBMs vs control diet. Collectively, the results indicate that feeding of fermented SBMs during early phase are beneficial to the subsequent growth performance in broiler chicks. BF-SBM and YBF-SBM showed superior overall growth performance as compared with unfermented SBM and SPC. (Key Words: Fermented Soybean Meals, Growth Performance, Cecal Microbial Population, Villi Length, Broiler Chicks)
\end{abstract}

\section{INTRODUCTION}

Considerable changes in the growth performance of modern broilers have been achieved via intensive genetic selection (Zuidhof et al., 2014). Due to a continuous shortening of the growth period, emphasis has been placed on the early development after hatching. It is well known that the market weights of modern broilers has a linear

\footnotetext{
* Corresponding Author: B. K. An. Tel: +82-2-450-3995, Fax: +82-2-452-9946, E-mail: abk7227@hanmail.net

${ }^{1}$ CJ Cheiljedang Ltd., Seoul 100-400, Korea.

Submitted Aug. 8, 2015; Revised Nov. 19, 2015; Accepted Jan. 26, 2016
}

relationship with their weight at the early phase of rearing (Nir et al., 1993). Therefore, the early feeding regime should be optimized to ensure the best start, which will result in better growth performance. But, the newly hatched chicks have an immature digestive system and are less efficient in utilizing nutrients (Batal and Parsons, 2002) and thus they could possibly benefit from diets containing easily digested ingredients.

Soybean meal (SBM) is the most commonly used vegetable protein source in feed industry. However, a huge variation of nutritional quality and a variety of antinutritional factors have limited the application of SBM in 
broiler feed (Lee et al., 2009). The carbohydrate fraction of SBM, which is primarily composed of non-starch polysaccharide and galactooligosaccharide is poorly utilized by poultry due to a lack of endogenous enzyme (Choct at al., 2010). Therefore, the value of nitrogen-corrected metabolizable energy (MEn) of SBM is about 30\% less for poultry as compared with swine due to its oligosaccharide fraction (NRC, 1994; 1998). Fermentation with microorganisms has been used to help degrade these antinutritional factors of SBM. The fermentation process is thought to reduce residual anti-nutritional factors such as trypsin inhibitor and to increase in small-size peptides (Hong et al., 2004). In addition, it is known that feeding of fermented SBM significantly increased the activities of digestive enzymes (trypsin, lipase, and protease) in intestinal contents of broiler chickens (Feng et al., 2007b).

In practice, supplementation of fermented SBMs is only applicable in pre-starter diet due to high cost burden. But there were no studies investigating the effect of fermented SBMs added into the pre-starter diet of broiler chicks on their subsequent growth. The objective of this experiment was to evaluate the subsequent growth and physiological response of broiler chicks fed pre-starter diets including fermented SBM products.

\section{MATERIALS AND METHODS}

\section{Animals, diets and management}

On the day of hatch, the male broiler chicks (Ross 308) were obtained from a local hatchery and individually weighed. A total of nine hundred chicks were randomly allotted to six groups with six replicates of 25 chicks each. Commercially available fermented SBMs were provided by the manufacturers. Bacillus fermented SBM (BF-SBM), yeast by product and Bacillus fermented SBM (YBF-SBM), Lactobacillus fermented SBM 1 (LF-SBM 1), Lactobacillus fermented SBM 2 (LF-SBM 2) and soy protein concentrate (SPC, Archer Daniels Midland Company, Chicago, IL, USA) were used for this study. BF-SBM (http://www.cjingredient. com/product/soytide.asp) is produced by the fermentation process with Bacillus subtillis and YBF-SBM is a two-stage-fermented SBM which brings probiotic effects. These are known to contain few anti- nutritional factors, such as oligosaccharides, trypsin inhibitor and lectins. LF-SBM 1 (http://www.dabombprotein.com.tw) and LF-SBM-2 (http:www.dachan.com) are fermented products that are produced by anaerobic fermentation of SBMs using Lactobacillus and known to contain at low levels of oligosaccharides. The chicks were fed control pre-starter diet with dehulled SBM or one of five experimental diets containing fermented SBM products or SPC for $7 \mathrm{~d}$ after hatching and switched to the grower and finisher diets without fermented SBMs and SPC for 4 wks. The fermented SBM products and SPC used in this study were provided by commercial feed manufactures and were substituted at the expense of dehulled SBM at 3\% level on fresh weight basis.

The fermented SBM products and SPC were first analyzed for moisture, crude protein $(\mathrm{CP})$, ether extract, crude fiber by the methods of AOAC (1995) and amino acid contents by amino acid analyzer (Sykam S433, Sykam $\mathrm{GmbH}$, Eresing, Germany), following hydrolysis in $6 \mathrm{~N}$ $\mathrm{HCl}$ for $22 \mathrm{~h}$ at $100^{\circ} \mathrm{C}$ (Spackman et al., 1958). Methionine and cysteine were determined from samples that had been oxidized in performic acid prior to acid hydrolysis according to the method of Moore (1963). Proximal compositions of the fermented SBM products and SPC are shown in Table 1. All pre-starter test diets were formulated to be equal in the contents of nitrogen-corrected true metabolizable energy (TMEn), CP and available amino acids and processed as a small crumble form (Table 2).

The chicks were initially reared at $33^{\circ} \mathrm{C}$; the room temperature was gradually decreased by $4^{\circ} \mathrm{C}$ weekly until a final temperature of $23^{\circ} \mathrm{C}$ was reached. Lighting was kept at 23/1 light/dark cycle throughout the experimental period. The chicks were allowed to have free access to diet and water. About 100 to $150 \mathrm{~g}$ of experimental diets per chick were provided every day at 08:00. All animal care procedures were approved by Institutional Animal Care and Use Committee in Konkuk University.

\section{Sampling and measurements}

The chicks and feed were weekly weighed per pen to calculate live body weight (BW), weight gain, feed intake and feed conversion ratio (FCR) on a pen basis. At $7 \mathrm{~d}$ of

Table 1. Proximal compositions of the dehulled soybean meal, fermented soybean meal products and soy protein concentrate

\begin{tabular}{lcccccc}
\hline & Dehulled SBM & BF-SBM & YBF-SBM & LF-SBM 1 & LF-SBM 2 & SPC \\
\hline Moisture (\%) & 12.3 & 6.21 & 6.25 & 4.74 & 7.04 & 6.31 \\
Crude protein (\%) & 47.4 & 56.37 & 55.23 & 50.40 & 51.29 & 66.67 \\
Ether extract (\%) & 2.5 & 0.99 & 1.56 & 1.43 & 1.64 & 0.11 \\
Crude fiber (\%) & 3.7 & 3.49 & 3.96 & 4.21 & 3.75 & 2.40 \\
Crude ash (\%) & 6.0 & 7.20 & 7.10 & 6.72 & 6.11 & 6.59 \\
\hline
\end{tabular}

BF-SBM, Bacillus fermented SBM (CJ Corporation, Seoul, Korea); YBF-SBM, yeast by product and Bacillus fermented SBM (CJ Corporation, Seoul, Korea); LF-SBM, Lactobacillus fermented SBM 1 (DaBomb Protein Corporation, Tainan, Taiwan); LF-SBM 2, Lactobacillus fermented SBM 2 (Total Nutrition Technologies Co., Ltd, Tainan, Taiwan); SPC, soy protein concentrate (Archer Daniels Midland Company, Chicago, IL, USA). 
Table 2. Formula and chemical compositions of pre-starter diets ${ }^{1}$

\begin{tabular}{|c|c|c|c|c|c|c|}
\hline & Control & BF-SBM & YBF-SBM & LF-SBM 1 & LF-SBM 2 & SPC \\
\hline Corn & 46.12 & 46.05 & 46.08 & 45.88 & 45.97 & 46.24 \\
\hline Wheat & 10.00 & 10.00 & 10.00 & 10.00 & 10.00 & 10.00 \\
\hline Corn gluten meal & 1.72 & 1.72 & 1.72 & 1.73 & 1.72 & 1.71 \\
\hline Wheat bran & 3.19 & 4.37 & 4.24 & 4.02 & 4.00 & 5.11 \\
\hline Soybean oil & 4.00 & 4.00 & 4.00 & 4.00 & 4.00 & 4.00 \\
\hline Soybean meal (imported) & 20.76 & 19.63 & 19.74 & 20.14 & 20.09 & 18.70 \\
\hline Soybean meal (dehulled) & 10.00 & 7.00 & 7.00 & 7.00 & 7.00 & 7.00 \\
\hline Fermented soybean meal & 0.00 & 3.00 & 3.00 & 3.00 & 3.00 & 0.00 \\
\hline Soy protein concentrate & 0.00 & 0.00 & 0.00 & 0.00 & 0.00 & 3.00 \\
\hline Lysine- $\mathrm{HCl}, 78 \%$ & 0.16 & 0.17 & 0.16 & 0.17 & 0.17 & 0.17 \\
\hline Dicalcium phosphate & 1.93 & 1.92 & 1.92 & 1.92 & 1.92 & 1.91 \\
\hline DL-methionine, $98 \%$ & 0.25 & 0.25 & 0.25 & 0.25 & 0.25 & 0.25 \\
\hline Limestone & 1.20 & 1.22 & 1.22 & 1.21 & 1.21 & 1.23 \\
\hline Choline- $\mathrm{Cl}, 50 \%$ & 0.08 & 0.09 & 0.09 & 0.09 & 0.09 & 0.10 \\
\hline Salt & 0.30 & 0.30 & 0.30 & 0.30 & 0.30 & 0.30 \\
\hline Vitamin mixture & 0.12 & 0.12 & 0.12 & 0.12 & 0.12 & 0.12 \\
\hline Mineral mixture & 0.15 & 0.15 & 0.15 & 0.15 & 0.15 & 0.15 \\
\hline $\mathrm{NaHCO}_{3}$ & 0.02 & 0.02 & 0.02 & 0.02 & 0.02 & 0.02 \\
\hline L-threonine, $98 \%$ & 0.02 & 0.02 & 0.02 & 0.02 & 0.02 & 0.02 \\
\hline \multicolumn{7}{|l|}{ Calculated nutrient content } \\
\hline Crude protein $(\%)$ & 20.50 & 20.50 & 20.50 & 20.50 & 20.50 & 20.50 \\
\hline $\mathrm{Ca}(\%)$ & 6.50 & 6.50 & 6.50 & 6.50 & 6.50 & 6.50 \\
\hline Available P (\%) & 0.45 & 0.45 & 0.45 & 0.45 & 0.45 & 0.45 \\
\hline Lysine (\%) & 1.20 & 1.20 & 1.20 & 1.20 & 1.20 & 1.20 \\
\hline Methionine (\%) & 0.57 & 0.57 & 0.57 & 0.57 & 0.57 & 0.57 \\
\hline Total TSAA (\%) & 0.92 & 0.92 & 0.92 & 0.92 & 0.92 & 0.92 \\
\hline TMEn $(\mathrm{kcal} / \mathrm{kg})$ & 3,080 & 3,080 & 3,080 & 3,080 & 3,080 & 3,080 \\
\hline
\end{tabular}

BF-SBM, Bacillus fermented SBM (CJ Corporation, Seoul, Korea); YBF-SBM, yeast by product and Bacillus fermented SBM (CJ Corporation, Seoul, Korea); LF-SBM 1, Lactobacillus fermented SBM 1 (DaBomb Protein Corporation, Tainan, Taiwan); LF-SBM 2, Lactobacillus fermented SBM 2 (Total Nutrition Technologies Co., Ltd, Tainan, Taiwan); SPC, soy protein concentrate (Archer Daniels Midland Company, Chicago, IL, USA); TSAA, total sulfur amino acid; TMEn, nitrogen-corrected true metabolizable energy.

${ }^{1}$ Vit. and Min. mixture provided the following nutrients per $\mathrm{kg}$ of diet: vitamin A, 40,000 IU; vitamin $\mathrm{D}_{3}, 8,000 \mathrm{IU}$; vitamin E, $10 \mathrm{IU}$; vitamin $\mathrm{K}_{3}, 4.0 \mathrm{mg}$; vitamin $\mathrm{B}_{1}, 4.0 \mathrm{mg}$; vitamin $\mathrm{B}_{2}, 12.0 \mathrm{mg}$; vitamin $\mathrm{B}_{6}, 6.0 \mathrm{mg}$; vitamin $\mathrm{B}_{12}, 0.02 \mathrm{mg}$; niacin, $60.0 \mathrm{mg}$; pantothenic acid, $20 \mathrm{mg}$; folic acid, $2.0 \mathrm{mg}$; biotin, $0.02 \mathrm{mg}$; Fe, $30.0 \mathrm{mg} ; \mathrm{Zn}, 25.0 \mathrm{mg}$; Mn, $20.0 \mathrm{mg}$; Cu, $5.0 \mathrm{mg}$; Se, $0.1 \mathrm{mg}$.

age, 8 chicks per treatment were selected, weighed individually and humanely euthanized by cervical dislocation. Immediately after euthanasia, small intestine was excised and 1-cm long segments were sampled from upper one-third region of the jejunum and distal two-third region of the ileum for histological measurement (Caruso et al., 2012). The segments from jejunum and ileum were fixed in $10 \%$ neutralized buffered formalin (BBC Biochemistry, Mount Vernon, WA, USA) and embedded in paraffin. The $4 \mu \mathrm{m}$ sections were stained with standard hematoxylin and eosin solution, and the cross sections were examined using a light microscope (Leica Microsystems DM 1000, Leica Microsystems, Wetzlar, Germany). Images were captured with a camera attached to the microscope (Leica Microsystems DFC 295, Leica Microsystems, Germany).

At the end of the experimental period, 8 chicks with similar BW per treatment were selected and weighed individually. The blood was drawn from wing vein using sterilized syringes for determination of the blood profiles. The concentrations of serum total protein, albumin, and blood urea nitrogen (BUN) were measured according to the colorimetric methods using biochemical analyzer (Hitachi modular system, Hitachi Ltd., Tokyo, Japan). At necropsy, liver, spleen, bursa of Fabricius, abdominal fat, right breast muscle were immediately removed and weighed. The relative weights of these organs were expressed as a percentage of live body weight.

The cecal content from each chick was aseptically sampled for microbial test at $7 \mathrm{~d}$ of age and the end of experiment. The cecal digesta homogenates in phosphatebuffered saline were serially diluted from $10^{-1}$ to $10^{-7}$. Dilutions were subsequently plated on duplicate selective agar media for enumeration of target bacterial strains. Total microbes, coliforms, Lactobacillus spp. and Bacillus spp. were enumerated using plate count agar, MacConkey agar, 
MRS agar and Mannitol egg yolk polymyxin (MYP) agar, respectively. Each plate was incubated at $37^{\circ} \mathrm{C}$, for 24 to 72 $\mathrm{h}$ anaerobically or aerobically, and colonies were then counted. Results obtained were presented as base-10 logarithm colony-forming units per gram of cecal digesta.

\section{Statistical analysis}

Data were analyzed by the general linear model procedure of the SAS (SAS, 2002) with pen means as the experimental units for evaluating growth performances, and individual birds as the experimental unit for the other criteria. The significant differences of obtained means were determined using Duncan's multiple range test at the level of $\mathrm{p}<0.05$ (Duncan, 1955).

\section{RESULTS AND DISCUSSION}

The changes in weekly BW of broiler chicks fed diets with fermented SBM products are shown in Figure 1. The BW at $7 \mathrm{~d}$ of age was not different between dietary treatments. The BW in chicks fed the pre-starter diets containing BF-SBM and YBF-SBM were significantly higher $(\mathrm{p}<0.05)$ compared with that in the control group at $14 \mathrm{~d}$ onwards. Chicks fed the pre-starter diets containing BF-SBM, YBF-SBM, and LF-SBM 2 gained more weight compared with the control-diet fed chicks during growing phase and total rearing period.

Growth performance (feed intake, daily weight gain, and FCR) of broiler chicks fed diets with fermented SBM products during early phase is shown in Table 3 . The feed intake during grower and finisher phases was not affected by dietary treatments. The daily weight gain in chicks fed diet containing YBF-SBM had the highest value $(p<0.01)$ during grower phase and followed by BF-SBM group. The changes in daily body weight gain during finisher phase and total rearing period were similar to that of grower phase. The daily weight gains in chicks fed diets containing YBFSBM, BF-SBM, and LF-SBM 2 were significantly higher $(p<0.001)$ than those of control and group with LF-SBM1 during total rearing period. At $21 \mathrm{~d}$ of age, there was no significant difference in FCR among groups. When data were pooled for total rearing period, the FCR in groups with BF-SBM, YBF-SBM, and LF-SBM 2 were significantly lower $(p<0.01)$ than those of control and group with SPC.

The earlier study by Chah et al. (1975) reported that diets with full fat soybean fermented by Aspergillus improved the growth performance and feed efficiency in broiler chicks. The replacing conventional SBM with fermented SBM in diets enhanced the BW gain in chicks (Hirabayashi et al., 1998; Feng et al., 2007a). It has been also suggested that fermented SBM may replace fish meal in diets fed to broiler chicks without reducing growth

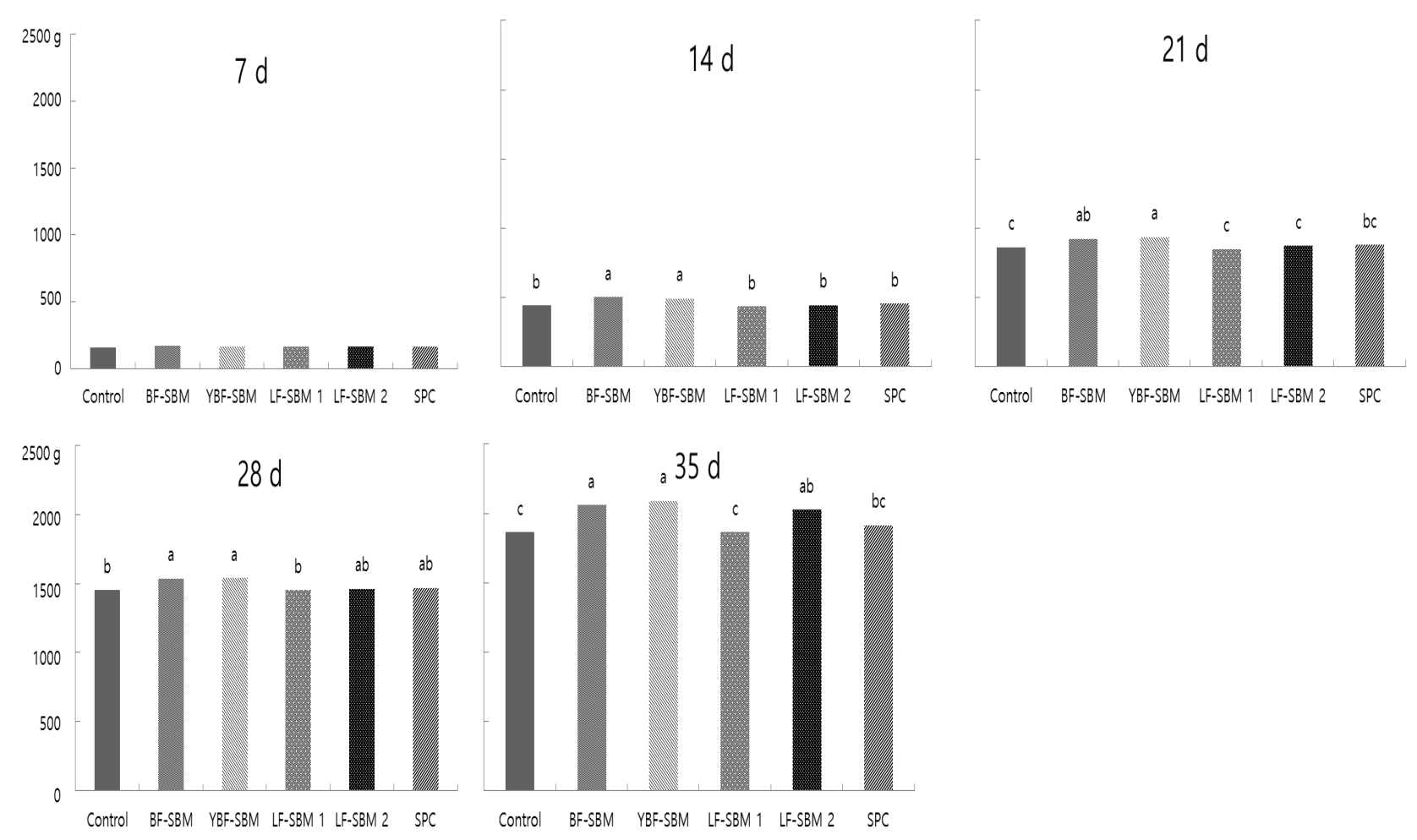

Figure 1. The change in weekly body weight of broiler chicks fed diets with fermented soybean meal (SBM) products during $7 \mathrm{~d}$ after hatching. BF-SBM, Bacillus fermented SBM; YBF-SBM, yeast by product and Bacillus fermented SBM; LF-SBM 1, Lactobacillus fermented SBM 1; LF-SBM 2, Lactobacillus fermented SBM 2; SPC, soy protein concentrate. ${ }^{\mathrm{a}-\mathrm{c}}$ Means within a row without a common superscript letter differ $(\mathrm{p}<0.05)$. 
Table 3. Growth performance of broiler chicks fed diets with fermented SBM products during $7 \mathrm{~d}$ after hatching

\begin{tabular}{lcccccccc}
\hline & Control & BF-SBM & YBF-SBM & LF-SBM 1 & LF-SBM 2 & SPC & SEM & p-value \\
\hline Feed intake (g/bird) & & & & & & & & \\
1-21 d & 60.5 & 60.04 & 60.9 & 58.9 & 59.3 & 59.7 & 0.88 & 0.631 \\
22-35 d & 132.3 & 140.9 & 140.5 & 130.1 & 138.3 & 137.2 & 2.79 & 0.058 \\
1-35 d & 88.7 & 91.5 & 91.6 & 86.5 & 89.8 & 89.9 & 1.26 & 0.080 \\
Body weight gain (g/bird) & & & & & & & \\
1-21 d & $39.1^{\mathrm{c}}$ & $42.0^{\mathrm{ab}}$ & $42.6^{\mathrm{a}}$ & $38.5^{\mathrm{c}}$ & $39.5^{\mathrm{c}}$ & $39.9^{\mathrm{bc}}$ & 0.78 & 0.006 \\
22-35 d & $71.5^{\mathrm{b}}$ & $80.5^{\mathrm{a}}$ & $80.9^{\mathrm{a}}$ & $70.6^{\mathrm{b}}$ & $80.9^{\mathrm{a}}$ & $72.8^{\mathrm{b}}$ & 2.39 & 0.006 \\
1-35 d & $52.0^{\mathrm{c}}$ & $57.7^{\mathrm{a}}$ & $58.5^{\mathrm{a}}$ & $52.0^{\mathrm{c}}$ & $56.7^{\mathrm{ab}}$ & $53.5^{\mathrm{bc}}$ & 1.12 & $<0.001$ \\
FCR (feed/gain) & & & & & & & & \\
1-21 d & 1.54 & 1.43 & 1.43 & 1.53 & 1.50 & 1.50 & 0.04 & 0.171 \\
22-35 d & $1.85^{\mathrm{ab}}$ & $1.75^{\mathrm{bc}}$ & $1.74^{\mathrm{bc}}$ & $1.85^{\mathrm{ab}}$ & $1.71^{\mathrm{c}}$ & $1.89^{\mathrm{a}}$ & 0.05 & 0.050 \\
1-35 d & $1.70^{\mathrm{a}}$ & $1.58^{\mathrm{bc}}$ & $1.57^{\mathrm{c}}$ & $1.66^{\mathrm{ab}}$ & $1.58^{\mathrm{bc}}$ & $1.69^{\mathrm{a}}$ & 0.03 & 0.008 \\
\hline
\end{tabular}

BF-SBM, Bacillus fermented SBM (CJ Corporation, Seoul, Korea); YBF-SBM, yeast by product and Bacillus fermented SBM (CJ Corporation, Seoul, Korea); LF-SBM 1, Lactobacillus fermented SBM 1 (DaBomb Protein Corporation, Tainan, Taiwan); LF-SBM 2, Lactobacillus fermented SBM 2 (Total Nutrition Technologies Co., Ltd, Tainan, Taiwan); SPC, soy protein concentrate (Archer Daniels Midland Company, Chicago, IL, USA); SEM, standard error of the means.

${ }^{\mathrm{a}-\mathrm{c}}$ Means within a row without a common superscript letter differ $(\mathrm{p}<0.05)$.

performance, but not conventional SBM (Li et al., 2014). Thus, instead of conventional SBM or fish meal, fermented SBMs are usually used as protein sources in diets for starter chicks. In this study, the use of fermented SBMs during early phase affected subsequent growth performance in broiler chicks, except for LF-SBM 1. The interpretation of difference in growth performance among fermented SBMs has remained difficult because all test diets were formulated to be equal in the contents of TMEn, CP, and available amino acids. However, the improvement of subsequent growth may be attributed to beneficial changes seen in microbial profiles due to feeding of some fermented SBMs. The fermentation process is thought to reduce residual antinutritional factors such as trypsin inhibitor and increase in small-size peptides. Feeding of fermented SBM significantly increased the activities of digestive enzymes in intestinal contents of broiler chickens (Feng et al., 2007b). It is also likely that the improvement of subsequent growth in chicks that had been fed some fermented SBMs during early phase may be associated with the diminution of antinutritional factors or changes in peptide size by proper fermentation.

At $35 \mathrm{~d}$, no significant differences in relative weights of liver, spleen, bursa of Fabricius, breast meat and abdominal fat were observed between dietary treatments (Table 4). At $35 \mathrm{~d}$, the concentrations of serum total protein, albumin and BUN were not affected by any of dietary treatments (Table 5). Feng et al. (2007a) reported that the serum urea nitrogen in chicks fed diet with higher levels of fermented SBM (295 $\mathrm{g} / \mathrm{kg}$ feed during 0 to 3 wks and $270 \mathrm{~g} / \mathrm{kg}$ feed during 4 to 6 wks) was significantly decreased as compared with that of control with conventional SBM. The decreased level of urea nitrogen represents that the chicks fed diets with fermented SBM utilized dietary nitrogen efficiently. It is likely that the observed discrepancy may be attributed to differences in feeding levels and duration of treatment as we added fermented SBM in starter diet at the level of 3\%.

The cecal microbial populations of broiler chicks fed diets with fermented SBM products during early phase are shown in Table 6. At $7 \mathrm{~d}$ of age, the number of total microbes in control group was significantly lower $(\mathrm{p}<0.001)$ than those of other groups. Whereas, the number of total microbes in groups with YBF-SBM, LF-SBM 2, and SPC were significantly higher $(\mathrm{p}<0.001)$ than those of other groups at termination of experiment. At $7 \mathrm{~d}$ of age, the number of lactic acid bacteria in groups with YBF-SBM

Table 4. Carcass characteristics of broiler chicks fed diets with fermented SBM products during $7 \mathrm{~d}$ after hatching

\begin{tabular}{lcccccccc}
\hline & Control & BF-SBM & YBF-SBM & LF-SBM 1 & LF-SBM 2 & SPC & SEM & p-value \\
\hline Liver (g/100 g BW) & 2.2 & 2.4 & 2.4 & 2.6 & 2.5 & 2.4 & 0.14 & 0.445 \\
Spleen (g/100 g BW) & 0.11 & 0.09 & 0.09 & 0.08 & 0.09 & 0.09 & 0.01 & 0.812 \\
Bursa of Fabricius (g/100 g BW) & 0.14 & 0.14 & 0.14 & 0.16 & 0.14 & 0.16 & 0.01 & 0.804 \\
Right breast muscle (g/100 g BW) & 9.0 & 9.3 & 9.8 & 9.1 & 8.9 & 9.1 & 0.27 & 0.217 \\
Abdominal fat (g/100 g BW) & 1.3 & 1.2 & 1.3 & 1.3 & 1.3 & 1.1 & 0.09 & 0.657 \\
\hline
\end{tabular}

BF-SBM, Bacillus fermented SBM (CJ Corporation, Seoul, Korea); YBF-SBM, yeast by product and Bacillus fermented SBM (CJ Corporation, Seoul, Korea); LF-SBM 1, Lactobacillus fermented SBM 1 (DaBomb Protein Corporation, Tainan, Taiwan); LF-SBM 2, Lactobacillus fermented SBM 2 (Total Nutrition Technologies Co., Ltd, Tainan, Taiwan); SPC, soy protein concentrate (Archer Daniels Midland Company, Chicago, IL, USA); SEM, standard error of the means. 
Table 5. The blood profiles of broiler chicks fed diets with fermented SBM products during $7 \mathrm{~d}$ after hatching

\begin{tabular}{lcccccccc}
\hline & Control & BF-SBM & YBF-SBM & LF-SBM 1 & LF-SBM 2 & SPC & SEM & p-value \\
\hline Total protein (g/dL) & 3.4 & 3.5 & 3.3 & 3.5 & 3.2 & 3.1 & 0.15 & 0.249 \\
Blood urea nitrogen (mg/dL) & 3.1 & 3.0 & 3.2 & 3.2 & 3.1 & 3.3 & 0.18 & 0.888 \\
Albumin (g/dL) & 1.4 & 1.3 & 1.3 & 1.3 & 1.4 & 1.3 & 0.06 & 0.370 \\
\hline
\end{tabular}

BF-SBM, Bacillus fermented SBM (CJ Corporation, Seoul, Korea); YBF-SBM, yeast by product and Bacillus fermented SBM (CJ Corporation, Seoul, Korea); LF-SBM 1, Lactobacillus fermented SBM 1 (DaBomb Protein Corporation, Tainan, Taiwan); LF-SBM 2, Lactobacillus fermented SBM 2 (Total Nutrition Technologies Co., Ltd, Tainan, Taiwan); SPC, soy protein concentrate (Archer Daniels Midland Company, Chicago, IL, USA); SEM, standard error of the means.

Table 6. The cecal microbial profiles of broiler chicks fed diets with fermented SBM products during $7 \mathrm{~d}$ after hatching

\begin{tabular}{|c|c|c|c|c|c|c|c|c|}
\hline & Control & BF-SBM & YBF-SBM & LF-SBM 1 & LF-SBM 2 & SPC & SEM & p-value \\
\hline \multicolumn{9}{|c|}{ Total microbes $(\log 10 \mathrm{cfu} / \mathrm{g})$} \\
\hline 7 days & $5.3^{\mathrm{b}}$ & $5.9^{\mathrm{a}}$ & $5.9^{\mathrm{a}}$ & $5.9^{\mathrm{a}}$ & $6.1^{\mathrm{a}}$ & $6.1^{\mathrm{a}}$ & 0.11 & $<0.001$ \\
\hline 35 days & $5.2^{\mathrm{b}}$ & $5.2^{\mathrm{b}}$ & $5.5^{\mathrm{a}}$ & $5.1^{\mathrm{b}}$ & $5.4^{\mathrm{a}}$ & $5.4^{\mathrm{a}}$ & 0.06 & $<0.001$ \\
\hline \multicolumn{9}{|c|}{ Lactic acid bacteria $(\log 10 \mathrm{cfu} / \mathrm{g})$} \\
\hline 7 days & $5.5^{\mathrm{b}}$ & $5.5^{\mathrm{b}}$ & $6.4^{\mathrm{a}}$ & $4.8^{\mathrm{c}}$ & $4.6^{\mathrm{c}}$ & $4.9^{\mathrm{bc}}$ & 0.19 & $<0.001$ \\
\hline 35 days & $4.4^{\mathrm{b}}$ & $5.1^{\mathrm{a}}$ & $5.0^{\mathrm{a}}$ & $4.3^{\mathrm{b}}$ & $4.3^{\mathrm{b}}$ & $4.3^{\mathrm{b}}$ & 0.06 & $<0.001$ \\
\hline \multicolumn{9}{|c|}{ Coliforms $(\log 10 \mathrm{cfu} / \mathrm{g})$} \\
\hline 7 days & 5.4 & 5.5 & 5.4 & 5.4 & 5.5 & 5.3 & 0.14 & 0.411 \\
\hline 35 days & $5.0^{\mathrm{a}}$ & $4.4^{\mathrm{b}}$ & $4.2^{\mathrm{b}}$ & $5.2^{\mathrm{a}}$ & $5.1^{\mathrm{a}}$ & $5.2^{\mathrm{a}}$ & 0.15 & $<0.001$ \\
\hline \multicolumn{9}{|c|}{ Bacillus spp. $(\log 10 \mathrm{cfu} / \mathrm{g})$} \\
\hline 35 days & $5.9^{\mathrm{b}}$ & $7.3^{\mathrm{a}}$ & $7.2^{\mathrm{a}}$ & $6.4^{\mathrm{b}}$ & $7.1^{\mathrm{a}}$ & $6.9^{\mathrm{a}}$ & 0.16 & $<0.001$ \\
\hline
\end{tabular}

BF-SBM, Bacillus fermented SBM (CJ Corporation, Seoul, Korea); YBF-SBM, yeast by product and Bacillus fermented SBM (CJ Corporation, Seoul, Korea); LF-SBM 1, Lactobacillus fermented SBM 1 (DaBomb Protein Corporation, Tainan, Taiwan); LF-SBM 2, Lactobacillus fermented SBM 2 (Total Nutrition Technologies Co., Ltd, Tainan, Taiwan); SPC, soy protein concentrate (Archer Daniels Midland Company, Chicago, IL, USA); SEM, standard error of the means.

${ }^{\mathrm{a}-\mathrm{c}}$ Means within a row without a common superscript letter differ $(\mathrm{p}<0.05)$.

had the highest value $(\mathrm{p}<0.001)$. The number of lactic acid bacteria in groups with BF-SBM and YBF-SBM were significantly higher $(\mathrm{p}<0.001)$ than other groups at the end of experiment. The number of coliform bacteria in groups with BF-SBM and YBF-SBM were significantly lower $(\mathrm{p}<0.001)$ than other groups at $35 \mathrm{~d}$, but not at $7 \mathrm{~d}$. At $35 \mathrm{~d}$, the number of Bacillus spp. in groups with fermented SBM and SPC were significantly higher $(\mathrm{p}<0.001)$ than that of control, except for LF-SBM 1. In this study, fermented SBMs such as BF-SBM, YBF-SBM, and LF-SBM 2, positively modulated the populations of cecal microflora, resulting in a potential probiotic effect. Jeong and Kim (2015) also found that dietary supplementation of fermented SBMs led to increased fecal Lactobacillus counts in weaned piglets. These findings suggest that fermented SBMs are the carrier of probiotics and can be used valuable feed ingredients in growing animals.

Villi length of 7-d-old chicks fed diets with fermented SBM products is shown in Table 7. The jejunal villi length in chicks fed diets with fermented SBMs and SPC was significantly longer $(\mathrm{p}<0.001)$ compared with the control group. Ileal villi length in groups with YBF-SBM and LFSBM1 tended to be higher than that of the control group, but the statistical difference was not noted. On the other hand, SPC-fed chicks exhibited the lowest ileal villi length $(p<0.05)$. Our study is in line with the previous studies. For example, Mathivanna et al. (2006) reported that the increased length and width of ileal villi were observed in broiler chicks fed diet with $0.5 \%$ and $1.0 \%$ fermented SBM. The positive changes of duodenal and jejunal villus height were also observed in chickens fed diet containing higher levels of fermented SBM (Feng et al., 2007b). Similarly,

Table 7. Effect of fermented soybean meal (SBM) on intestinal villi length in 7-d-old broiler chicks during $7 \mathrm{~d}$ after hatching

\begin{tabular}{lcccccccc}
\hline & Control & BF-SBM & YBF-SBM & LF-SBM 1 & LF-SBM 2 & SPC & SEM & p-value \\
\hline Jejunum & $412.6^{\mathrm{b}}$ & $536.1^{\mathrm{a}}$ & $522.3^{\mathrm{a}}$ & $572.9^{\mathrm{a}}$ & $498.8^{\mathrm{a}}$ & $533.3^{\mathrm{a}}$ & 24.9 & $<0.001$ \\
Ileum & $424.4^{\mathrm{ab}}$ & $395.9^{\mathrm{ab}}$ & $435.7^{\mathrm{a}}$ & $434.5^{\mathrm{a}}$ & $407.0^{\mathrm{ab}}$ & $369.2^{\mathrm{b}}$ & 19.3 & 0.044 \\
\hline
\end{tabular}

BF-SBM, Bacillus fermented SBM (CJ Corporation, Seoul, Korea); YBF-SBM, yeast by product and Bacillus fermented SBM (CJ Corporation, Seoul, Korea); LF-SBM 1, Lactobacillus fermented SBM 1 (DaBomb Protein Corporation, Tainan, Taiwan); LF-SBM 2, Lactobacillus fermented SBM 2 (Total Nutrition Technologies Co., Ltd, Tainan, Taiwan); SPC, soy protein concentrate (Archer Daniels Midland Company, Chicago, IL, USA); SEM, standard error of the means.

${ }^{\mathrm{a}, \mathrm{b}}$ Means within a row without a common superscript letter differ $(\mathrm{p}<0.05)$. 
fermented diet-fed weanling piglets exhibited higher villi height and villus height to crypt depth ratio (Scholten et al., 2002). The improvement of intestinal morphology in fermented SBMs-fed young animals may be likely due to the higher lactic acid level and the diminution of antinutritional factors presented in fermented feed (Hong et al., 2004; Mathivanna et al., 2006). It is suggested that an increased villi length is paralleled by an increased digestive and absorptive function of small intestine, which can lead to better nutrient absorption (Caspary, 1992) and overall growth performance (Feng et al., 2007b). Thus, some fermented SBMs used in this study had beneficial effects on villi morphology in starter chicks and these might be partially responsible for the subsequent growth.

\section{CONCLUSION}

The results indicate that feeding of some fermented SBMs during early phase are beneficial to the subsequent growth performance in broiler chicks through good impacts on intestinal morphology and microbial profiles. Especially, BF-SBM and YBF-SBM showed superior overall growth performance as compared with unfermented SBM and SPC.

\section{CONFLICT OF INTEREST}

We certify that there is no conflict of interest with any financial organization regarding the material discussed in the manuscript.

\section{ACKNOWLEDGMENTS}

This paper was supported by the KU Research Professor Program of Konkuk University and National Institute of Animal Science, RDA (No. PJ01189801).

\section{REFERENCES}

AOAC (Association of Official Analytical Chemists) International. 1995. Official Methods of Analysis, 16th edn. Arlington, VA, USA.

Batal, A. B. and C. M. Parsons. 2002. Effect of fasting versus feeding oasis after hatching on nutrient utilization in chicks. Poult. Sci. 81:853-859.

Caspary, W. F. 1992. Physiology and pathophysiology of intestinal absorption. Am. J. Clin. Nutr. 55:299S-308S.

Caruso, M., A. Demonte, and V. A. Neves. 2012. Histomorphometric study of role of lactoferrin in atrophy of the intestinal mucosa of rats. Health 4:1362-1370.

Chah, C. C., C. W. Carlson, G. Semeniuk, I. S. Palmer, and C. W. Hesseltine. 1975. Growth-promoting effects of fermented soybeans for broilers. Poult. Sci. 54:600-609.

Choct, M., Y. Dersjant-Li, J. McLeish, and M. Peisker. 2010. Soy oligosaccharides and soluble non-starch polysaccharides: A review of digestion, nutritive and anti-nutritive effects in pigs and poultry. Asian Australas J. Anim. Sci. 23:1386-1398.
Ducan, D. B. 1955. Multiple range and multiple F test. Biometrics $11: 1-42$.

Feng, J., X. Liu, Z. R. Xu, Y. Y. Liu, and Y. P. Lu. 2007a. Effects of Aspergillus oryzae 3.042 fermented soybean meal on growth performance and plasma biochemical parameters in broilers. Anim. Feed Sci. Technol. 134:235-242.

Feng, J., X. Liu, Z. R. Xu, Y. Z. Wang, and J. X. Liu. 2007b. Effects of fermented soybean meal on digestive enzyme activities and intestinal morphology in broilers. Poult. Sci. 86:1149-1154.

Hirabayashi, M., T. Matsui, H. Yano, and T. Nakajima. 1998. Fermentation of soybean meal with Aspergillus usamii reduces phosphorus excretion in chicks. Poult. Sci. 77:552-556.

Hong, K. J., C. H., Lee, and S. W. Kim. 2004. Aspergillus oryzae GB-107 fermentation improves nutritional quality of food soybeans and feed soybean meals. J. Med. Food 7:430-435.

Jeong, J. S. and I. H. Kim. 2015. Comparative efficacy of up to $50 \%$ partial fish meal replacement with fermented soybean meal or enzymatically prepared soybean meal on growth performance, nutrient digestibility and fecal microflora in weaned pigs. Anim. Sci. J. 86:624-633.

Lee, B. K., J. Y. Kim, J. S. Kim, S. J. You, B. K. An, E. J. Kim, and C. W. Kang. 2009. Nutritional value of soybean meal from various geographic origin and effect of their dietary supplementation on performance of broilers. J. Anim. Sci. Technol. 51:217-224.

Li, C. Y., J. J. Lu, C. P. Wu, and T. F. Lien. 2014. Effects of probiotics and bremelain fermented soybean meal replacing fish meal on growth performance, nutrient retention and carcass traits of broilers. Livest. Sci. 163:94-101.

Mathivanan, R., P. Selvaraj, and K. Nanjappan. 2006. Feeding of fermented soybean meal on broiler performance. Int. J. Poult. Sci. 5:868-872.

Moore, S. 1963. On the determination of cystine as cysteic acid. J. Biol. Chem. 238:235-237.

Nir, I., Z. Nitsan, and M. Mahagna. 1993. Comparative growth and development of digestive organs and of some enzymes in broiler and egg type chicks after hatching. Br. Poult. Sci. 34:523-532.

NRC (National Research Council). 1994. Nutrient Requirements of Poultry. 9th edn. National Academy Press, Washington, DC, USA.

NRC (National Research Council). 1998. Nutrient Requirements of Swine. 10th rev. edn. National Academy Press, Washington, DC, USA.

SAS (Statistical Analysis System) Institute. 2002. SAS User's Guide. Statistics, version. 8edn. Statistical Analysis System Institute. Inc., Cary, NC, USA.

Scholten, R. H. J., C. M. C. Van der Peet-Schwering, L. A. den Hartog, M. Balk, J. W. Schrama, and M. W. A. Verstegen. 2002. Fermented wheat in liquid diets: Effects on gastrointestinal characteristics in weanling piglets. J. Anim. Sci. 80:1179-1186.

Spackman, D. H., W. H. Stein, and S. Moore. 1958. Automatic recording apparatus for use in the chromatography of amino acid. Anal. Chem. 30:1190-1206.

Zuidhof, M. J., B. L. Schneider, V. L. Carney, D. R. Korver, and F. E. Robinson. 2014. Growth, efficiency, and yield of commercial boilers from 1957, 1873, and 2005. Poult. Sci. 93:2970-2982. 